\title{
Cellulite: a review with a focus on subcision
}

This article was published in the following Dove Press journal:

Clinical, Cosmetic and Investigational Dermatology

7 January 2017

Number of times this article has been viewed

\section{Daniel P Friedmann' \\ Garrett Lane Vick ${ }^{2}$ \\ Vineet Mishra ${ }^{3}$ \\ 'Westlake Dermatology Clinical Research Center, Westlake Dermatology \& Cosmetic Surgery, Austin, ${ }^{2}$ Department of Medicine, ${ }^{3}$ Division of Dermatology and Cutaneous Surgery, The University of Texas Health Science Center at San Antonio, San Antonio, TX, USA}

\begin{abstract}
Cellulite is an alteration in skin topography most often found on the buttocks and posterolateral thighs of the majority of postpubertal females. This article aims to review the background, potential pathophysiology, and potential treatment options for cellulite, highlighting subcision as an ideal therapeutic option for this cosmetically distressing condition.
\end{abstract}

Keywords: gynoid lipodystrophy, fibrous septae, radiofrequency, vacuum-assisted subscision

\section{Introduction}

Cellulite is a descriptive term used to characterize the cosmetically distressing, altered (eg, dimpled, padded, peau d'orange) topography of skin located most commonly on the outer thighs, posterior thighs, and buttocks of the majority of postpubertal females. ${ }^{1}$ First described in the early 20th century, it has been referred to by several synonyms, including gynoid lipodystrophy, nodular liposclerosis, edematofibrosclerotic panniculopathy, panniculosis, adiposis edematosa, dermopanniculosis deformans, and status protrusus cutis. ${ }^{2-4}$ Many modalities, including subcision, have been purported to treat cellulite. This article aims to review the background, potential pathophysiology, and potential treatment options for cellulite, highlighting subcision as an ideal therapeutic modality for this condition.

\section{Epidemiology}

Despite its high prevalence ( $80 \%-90 \%)$ in postpubertal female patients of all races, little epidemiologic data on its exact prevalence, incidence, and associating factors have been published. ${ }^{5}$ Cellulite may worsen during high estrogen states, including pregnancy, nursing, and chronic use of oral contraceptives. Although diet, exercise, and lifestyle, however, do not appear to be associated with its development, weight gain and obesity can worsen the appearance of existing cellulite.

Cellulite in male patients is rare and a product of androgen deficiency secondary to castration, hypogonadism, Klinefelter's syndrome, or estrogen therapy for prostate cancer. $^{3}$

\section{Pathophysiology}

Cellulite is multifactorial, with sexual dimorphism of subcutaneous connective tissue, the effects of localized increases in tissue tension, and local circulatory and inflammatory abnormalities all thought to play an important role. ${ }^{3,6}$ 
Nürnberger and Müller ${ }^{4}$ first proposed that topographic alterations of cellulite skin were caused by fat herniation into a weakened dermis. Although Mirrashed et $\mathrm{al}^{7}$ demonstrated, by magnetic resonance imaging (MRI), that cellulite grade correlated with the percentage of hypodermic invaginations into the dermis, Pierard et $a l^{8}$ were unable to find a correlation between fat protrusions and the clinical appearance of cellulite. Instead, they proposed that continuous and progressive tension placed on vertically oriented subcutaneous fibrous septae tethered to the underside of the dermis by fat accumulation that alters the dermal-subcutaneous interface, creating dimples and depressions. ${ }^{9}$ Bulging of partitioned subcutaneous fat lobules peripherally and superficially occurs as a secondary event. In fact, the morphology of subcutaneous fat from cellulite compared with control skin has been shown to be equivalent by MRI and histopathologic examination..$^{10,11}$

MRI and transmission electron micrograph studies have confirmed that cellulite depressions are associated with a significant increase in the presence and thickness of underlying subcutaneous fibrous septa. ${ }^{12,13}$ Although fibrous septa can be found parallel to the skin surface, tilted at $45^{\circ}$, or perpendicular to the skin surface, females with cellulite have a greater percentage of perpendicular septa compared with males or females without cellulite. ${ }^{14}$ Greater tension on these fibrous septae from standing, pinching, or active muscle contraction (due to communication with the underlying musculoaponeurotic system) worsens their clinical appearance, whereas they tend to disappear when tension is minimized with the patient lying down.

Alterations in the vascular and lymphatic microcirculation of subcutaneous adipose tissue have also been purported to play an underlying role in cellulite formation. Curri ${ }^{15}$ proposed that cellulite is the result of dermal vascular and metabolic changes similar to those found in chronic venous stasis. ${ }^{3}$ The combination of altered precapillary arteriolar sphincters increasing capillary permeability and glycosaminoglycan (GAG) deposition in capillary walls attracting water would lead to dermal edema, with subsequent vascular congestion, capillary network loss, and tissue hypoxia. ${ }^{13,15}$ Hypoxia and GAG deposition would, in turn, elicit neovascularization and thickening and sclerosis of fibrous septae. Although Lotti et al ${ }^{16}$ confirmed the presence of extracellular GAG in the dermal ground substance of cellulite-affected skin, Querleux et a ${ }^{14}$ did not demonstrate increased water at the dermal-subcutaneous junction. $A C E$ rs1799752 and HIFIA rs11549465 gene polymorphisms in subcutaneous tissue have also been associated with cellulite; the former may increase ACE activity and disturbances in tissue oxygenation, whereas the latter is protective against fibroinflammatory and microhypoxic tissue responses. ${ }^{17}$ Nevertheless, biopsy examination of cellulite by Rosenbaum et al ${ }^{11}$ did not show significant differences in regional blood flow between cellulite and control sites.

Inflammatory factors have been associated with the pathogenesis of cellulite, with the thought that chronic inflammation may play a role in the fibrous septal development. Significant decreases in the subcutaneous expression of adiponectin, an adipocyte-derived hormone with antiinflammatory, antifibrotic, and vasodilatory functions, may also play a role in cellulite pathogenesis. ${ }^{18}$ Measures of cellular oxidative stress including serum malondialdehyde and plasma protein carbonyls may be increased in patients with cellulite. ${ }^{19}$

Cellulite may also be influenced by waist-to-hip ratio, but is not a result of increased body mass index (BMI) or the angle of lumbar lordosis. ${ }^{6,20}$ Idiopathic cyclic edema has been associated with more advanced cases of cellulite. ${ }^{21}$ The combination of smoking and $A C E$ gene polymorphism was significantly associated with cellulite risk. ${ }^{22}$

\section{Clinical features and severity grading}

Cellulite may affect any area with subcutaneous adipose tissue. Although most often observed in the outer thighs, posterior thighs, and buttocks, the hips, periumbilical abdomen, breasts, posterior arms, and posterior neck may be affected.

Cellulite must always be evaluated with patients standing in anatomic position. Pinching the affected areas with the thumb and index finger, having the patient contract the underlying muscle group, and the use of tangential hard light can all help accentuate and visualize contour irregularities in affected areas. ${ }^{1}$

Nürnberger and Müller ${ }^{4}$ proposed the first clinical grading scale for cellulite, dividing the condition into three grades with grades II and III further subclassified into mild, moderate, or severe. Grade I skin is smooth at rest, grade II skin demonstrates a mattress or orange peel appearance at rest, and grade III skin has grade II features and nodules intermixed with raised and depressed areas at rest.

Rossi and Vergnanini ${ }^{2}$ classified cellulite based on the presence and severity of clinical and histopathologic findings, from grades I to IV. Grade I cellulite is clinically inapparent but may have early positive histologic changes. Grade II cellulite is clinically inapparent at rest, but dimples or depressions become evident with skin pinching or muscular contraction. 
Grade III and IV cellulites are clinically apparent at rest, with the latter having significantly greater disease severity.

The first standardized and objective method of grading cellulite, the cellulite severity scale (CSS), was developed by Hexsel et al. ${ }^{23}$ This validated photonumeric CSS is based on 5 key morphologic aspects of cellulite, including the 1) number of depressions; 2) depth of depressions; 3 ) clinical morphology; 4) extent of skin laxity, flaccidity, or sagging; and 5) Nürnberger-Müller classification grade. Each variable is graded from 0 to 3, leading to overall grades of mild (1-5), moderate (6-10), and severe (11-15). De La Casa Almeida et $\mathrm{al}^{24}$ showed that this severity scale has excellent reliability and internal consistency when used to evaluate cellulite of the buttocks and posterior thighs. However, the study showed that laxity scoring is not essential, actually reducing the high internal consistency scores of the scale.

Several instrument-based measures for evaluating cellulite have been utilized in clinical studies, including imaging modalities (eg, ultrasound and MRI), biomechanical properties (eg, elasticity), and vascularity (eg, laser doppler flowmetry and thermography). ${ }^{25-27}$ Their clinical relevance remains arguable. Although photonumeric cellulite grading (5-point scale) and BMI were positively correlated with severity scores (10-point scale) in a study by Soares et al, ${ }^{28}$ high-frequency $(20 \mathrm{MHz})$ ultrasound results and skin elasticity scores were not. A study by Smalls et $\mathrm{al}^{29}$ also showed that biomechanical properties were not correlated with cellulite severity, but BMI and architecture of the dermal-subcutaneous junction were. Textural analysis has recently been shown to be a reliable method of objectively evaluating posterior thigh and buttock cellulite. ${ }^{30}$

\section{Treatment options}

Several therapies have been designed, marketed, and/or purported to improve cellulite, including topical therapy, injectables (eg, chemical septolysis with collagenase), lymphatic or vacuum-assisted massage, acoustic wave therapy, light therapy, external noninvasive lasers, and radiofrequency (RF) devices. ${ }^{31,32}$ Unfortunately, unpredictable efficacy and the potential for only short-term improvement despite numerous treatment sessions limit their popularity; although more invasive, subcision can lead to significant improvement in cellulite after just one treatment with limited downtime. ${ }^{33,34}$

\section{Topical therapy}

Numerous topical cosmeceutical ingredients, including methylxanthines (eg, caffeine), retinoids, and botanical extracts, have been reported to improve the appearance of cellulite. ${ }^{35}$
Stimulation of cutaneous microcirculation, promotion of lipolysis, and increased dermal neocollagenesis in response to these topicals may play a role.

\section{Physical decongestive therapy}

Combined positive and negative pressure from vacuumassisted mechanical massage or lymphatic drainage may promote venous microcirculation and lymphatic drainage, which helps redistribute extracellular fluid. ${ }^{36-38}$ Results with these time-consuming and technique-dependent treatments are decent, but like with topical therapy, transient. ${ }^{39,40}$

\section{Acoustic wave therapy}

Extracorporeal shock wave or pulse activation therapy may improve cutaneous microcirculation, neocollagenesis, and lymphatic drainage. ${ }^{41}$ Several studies have demonstrated improvement in cellulite appearance or grade after 6-8 weekly sessions. ${ }^{42-44}$

\section{RF devices}

RF devices generate heat due to resistance to the flow of an electrical current in target tissue, a phenomenon known as bioimpedance. Electrothermal energy production with this modality is monopolar (single electrode with return electrode), unipolar (single electrode with no return), bipolar ( 2 electrodes), or multipolar (3 or more electrodes). Because bipolar RF only has superficial clinical effects, it is often combined with other modalities, including mechanical massage and 700-2000 nm infrared energy. ${ }^{32}$

\section{Subcision}

Subcision is a surgical technique first described in 1995 that releases the reticular dermis from tethering by underlying fibrous septal bands within subcutaneous adipose tissue, resulting in smoother skin topography. ${ }^{45}$ The clinical improvement seen after severing of fibrous septations is likely also due in part to the redistribution of subcutaneous tension forces, mitigating fat protrusion, and reallocation of fat lobules into spaces created by the procedure. Subcision is recommended only for cellulite depressions present at rest, not for depressions visible only with muscle contraction. Depressions are marked immediately preprocedure with the patient standing in a relaxed position (Figure 1).

Direct percutaneous infiltration of dilute lidocaine $(0.1 \%)$ and sodium bicarbonate $(8.4 \%)$ with epinephrine $(1: 1,000,000)$ in physiologic saline produces complete local anesthesia and hemostasis of cutaneous and subcutaneous tissues, making this an outpatient procedure without the 


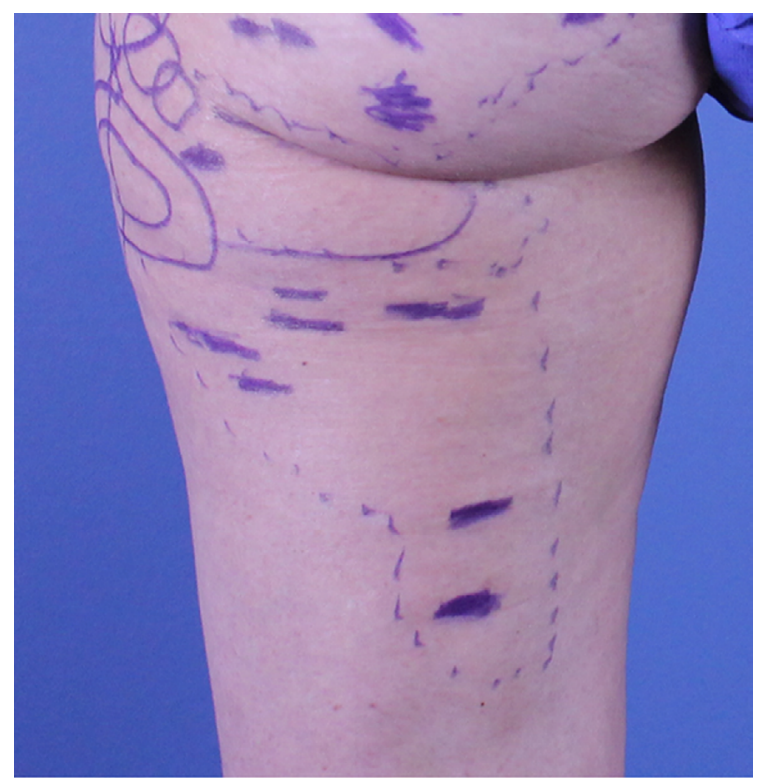

Figure I Cellulite depressions of the buttocks and posterior and lateral thighs marked with a surgical blue marker prior to subcision.

need for systemic anesthesia. ${ }^{46}$ The infiltrated fluid also hydraulically elevates subcutaneous tissue away from vital underlying structures, further enhancing safety. ${ }^{47}$ Tumescent fluid infiltration begins in the deepest subcutaneous layer, which leads to collateral partial anesthesia of overlying layers of fat, allowing for more tolerable superficial infiltration. Waiting for a minimum of 15 minutes after infiltration ensures maximal anesthesia and hemostasis. ${ }^{48}$

Prophylactic antibiotics are not required but may be considered in higher risk patients. Avoidance of strenuous physical activity for 1-2 weeks and use of a compressive garment for 2-4 weeks are recommended following any type of subcision. Subcision can be divided into manual, vacuum-assisted, and laser-assisted methods.

\section{Manual subcision}

A forked cannula or 18-G noncoring needle is inserted 10-20 $\mathrm{mm}$ into the subcutaneous adipose tissue layer, parallel to the skin surface. When using a noncoring needle, the cutting blade is positioned against a fibrous band, and pressure is maintained as the needle is withdrawn, leading to repetitive cutting motions until a dissection plane is created..$^{45}$ The depth of subcision is vital, given that subcision performed too superficially can result in excessive elevation or necrosis of the skin, whereas subcision performed too deep may produce negligible improvement in the targeted depressions. Not surprisingly, manual subcision is dependent on the skill and technique of the practitioner (Figure 2).

Uniform (eg, sandbag) or manual compression is then applied for 5-10 minutes to control bleeding from severed

\section{A}

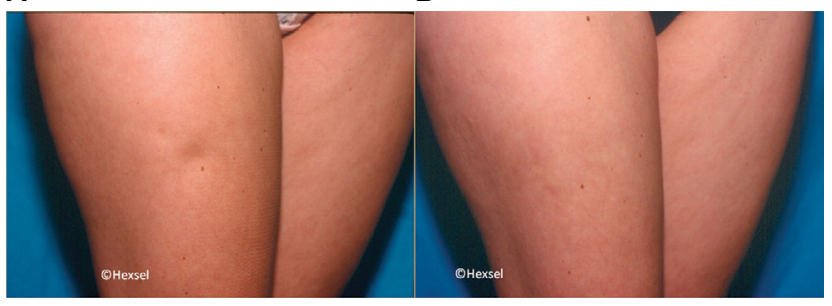

Figure 2 Significant improvement in a right anterolateral thigh cellulite depression before (A) and 30 days after (B) manual subcision.

Source: Photo courtesy of Doris Hexsel, MD.

vessels and prevent hematomas, while at the same time allowing for organized bruises that may enhance the formation of collagen and connective tissue. Individual areas should be no larger than $3 \mathrm{~cm}$, which helps avoid excessive bruising and dissection.

A retrospective study of 232 subjects with advanced cellulite of the buttocks/thighs by Hexsel and Mazzuco ${ }^{45}$ demonstrated $78.87 \%$ subject satisfaction after a single treatment. Twenty-three subjects $(9.91 \%)$ were followed up at 2 years and found to have persistent results. However, no objective or standardized grading criteria were utilized in this study. Only 2 subjects $(0.86 \%)$ were dissatisfied with their results, although 33 subjects (14.22\%) experienced excessive elevation of treated areas. Posttreatment adverse events also included painful bruising for up to 4 months in $90 \%$ of subjects and hemosiderin pigmentation for up to 10 months in all subjects, both of which resolved spontaneously without further treatment. Pretreatment iron supplementation and repeat subcision at 45-day follow-up were associated with greater hemosiderin pigmentation. Repeat manual subcision should, therefore, be avoided for at least 2 months from initial therapy or until all bruising or hemosiderin pigmentation from that first session has resolved.

A study of 2 subjects with severe buttock cellulite treated with a single session of manual subcision using an $18-\mathrm{G}$ noncoring needle demonstrated significant improvement in CSS scores at 1-month follow-up, with results maintained at 7 months posttreatment. ${ }^{33} \mathrm{CSS}$ scores of the left/right buttock were $13 / 13$ and $13 / 14$ at baseline, improving to $7 / 8$ and $9 / 9$ at 1,3 , and 7 months. MRI of a target lesion on each buttock of each patient, performed before and after treatment, showed severing of the underlying perpendicular thick fibrous septal band. Overall subcutaneous adipose tissue architecture and fat lobule morphology remained the same.

\section{Vacuum-assisted subcision}

Given the technique dependence and potential inconsistency of results with manual (free hand) subcision, a novel 
vacuum-assisted system (Cellfina system; Ulthera, Inc., Mesa, AZ, USA) was developed, providing precise control of anesthesia infiltration (integrated 22-G needle) and user-selected treatment depth $(6$ or $10 \mathrm{~mm})$ and area $(5 \mathrm{~cm}$ or $3 \times 6 \mathrm{~cm})$ with a $0.45 \mathrm{~mm}$ microblade. ${ }^{34,49}$ Tissue release is achieved by a combination of reciprocating (forward and backward) and lateral (side-to-side) microblade motions. Practitioners have reported significant single-session improvement without recurrence as far as 40 months posttreatment (Figure 3). ${ }^{49}$

A multicenter, open-label pivotal study by Kaminer et $\mathrm{al}^{34}$ evaluated a single treatment session of vacuum-assisted precise tissue release in 55 subjects with an average of 42 years (range, 25-55 years) and a mean of 13 released sites (range, 6-25). The primary release depth was $6 \mathrm{~mm}$, with the $10 \mathrm{~mm}$ depth used for sites immediately adjacent to the ones treated at $6 \mathrm{~mm}$, in order to prevent large contiguous areas with longer healing times and the potential for seroma formation.

Severity scores were assessed for the number (0-3) and average depth (0-3) of depressions in the treatment area, with a validated modified 6-point (0-5) CSS calculated by adding them and subtracting 1 . Statistically significant CSS score reductions (mean [SD]) from baseline (3.4 [0.8]; $\mathrm{N}=55)$ were seen at 3 months $(-2.1[0.7], p<0.0001 ; \mathrm{N}=55)$ and 1 year $(-2.0[0.8], p<0.0001 ; \mathrm{N}=50)$. The 6-point CSS was also converted into a qualitative cellulite severity grade $(0-3$; none, mild, moderate, and severe), with $92.7 \%$ and $94 \%$ of subjects demonstrating $\geq 1$ point improvement at 3 months and 1 year, respectively. Physician-graded global aesthetic improvement scale (GAIS) assessments showed noticeable improvement in $98.2 \%$ and $100 \%$ (and marked improvement in $74.5 \%$ and $72 \%$ ) of subjects at 3 months and 1 year, respectively. Subject satisfaction was $0 \%$ at baseline, $85 \%$ at

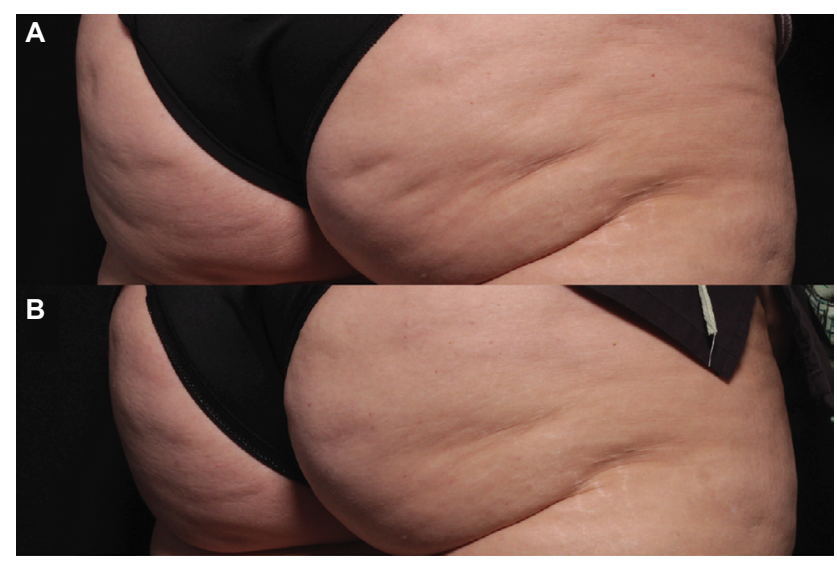

Figure 3 Significant improvement in cellulite of the buttocks 3 months following a single session of vacuum-assisted subcision (B) compared with baseline (A). Source: Photo courtesy of Douglas C. Wu, MD, PhD.
3 months, $88 \%$ at 6 months, and $94 \%$ at 1 year. Pain scores (0-10) were highest during infiltration (mean 4.5), with some subjects experiencing mild "aching" pain for up to 6 months posttreatment. Other adverse events, including ecchymosis, edema, palpable firmness, and tingling, were mild, transient, and resolved spontaneously.

\section{Laser-assisted subcision}

Targeted disruption of subcutaneous fibrous septae can also be performed with percutaneous subdermal delivery of laser energy (Figures 4 and 5). Although $1064 \mathrm{~nm}$ and $1320 \mathrm{~nm}$ laser wavelengths can be used effectively for this purpose, a $1440 \mathrm{~nm}$ device with a $1000 \mathrm{~m}$ side-firing laser fiber tip (Cellulaze system; Cynosure, Inc., Westford, MA, USA) has been shown to be safe and effective for the treatment of cellulite in multiple clinical studies.

A prospective study of 25 female subjects with a mean age of 40 (range, 27-67) years evaluated this device for advanced (mild-to-severe grade II and mild-to-moderate grade III) cellulite of the posterior and lateral thighs. ${ }^{50} \mathrm{Up}$ to $1500 \mathrm{~J}$ of energy $(8-10 \mathrm{~W}, 25 \mathrm{~Hz})$ was delivered to each $5 \times 5 \mathrm{~cm}$ treatment area, reaching subdermal target temperatures of $45^{\circ} \mathrm{C}-4^{\circ} \mathrm{C}\left(36^{\circ} \mathrm{C}-38^{\circ} \mathrm{C}\right.$ at the skin surface $)$. Independent physician and subjects GAIS scores showed mild improvement in cellulite severity at 6 months $(\mathrm{N}=20)$ and 2 years $(\mathrm{N}=16)$.

DiBernardo et $\mathrm{al}^{51}$ evaluated the same device for buttock and thigh cellulite in a multicenter study of 57 female subjects

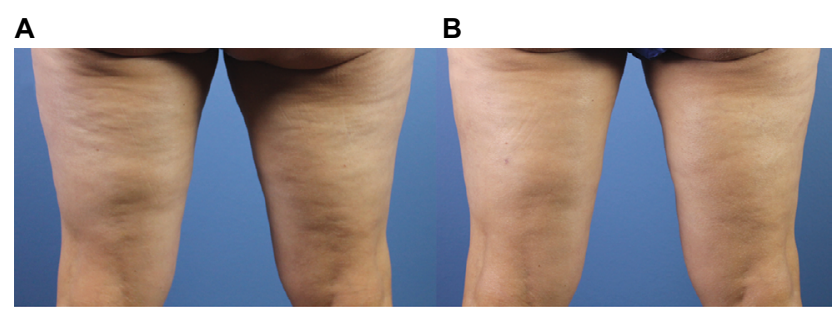

Figure 4 Before $(A)$ and 4 months after (B) laser-assisted subcision of the posterior thighs demonstrating significant improvement in skin contour.

A B

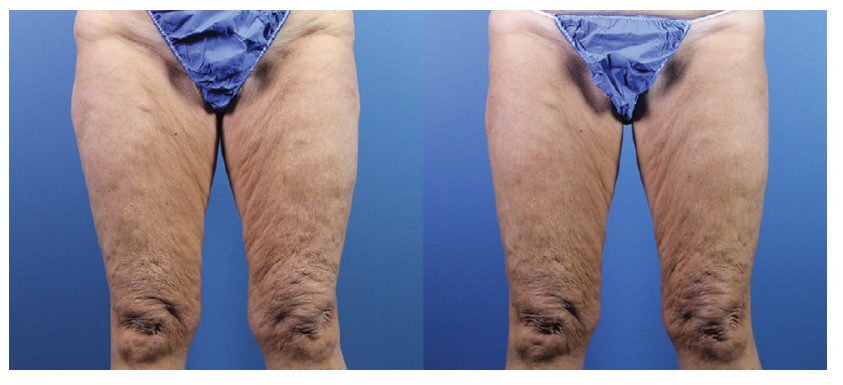

Figure 5 Improvement in anterior thigh cellulite and skin laxity 4 months following laser-assisted subcision (B) compared with baseline (A).

Note: Laser-assisted liposuction of the inner and outer thighs was also performed concurrently. 
with a mean age of 43.3 (range, 21-55) years. Three blinded independent physicians evaluated photographs for the severity of dimpling and contour irregularities, with each category graded using a validated 5-point (0-4) scale. The percent of treatment areas demonstrating $\geq 1$-point improvement in either dimple count or contour irregularity was $76 \%, 78 \%$, and $96 \%$ at 2, 3, and 6 months posttreatment. Follow-up evaluation at 1 year revealed that $90 \%$ of treated areas maintained a $\geq 1$-point improvement in both categories..$^{52}$ At least $90 \%$ of physicians and subjects reported satisfaction with results at 6 months. A similar study by Katz ${ }^{53}$ confirmed these findings, with $94 \%$ of subjects having $\geq 1$-point improvement in dimple count and contour irregularity at 6 months. 3D imaging also showed a mean decrease in dimpling of $49 \%$ and improvement in contour of $66 \%$ at the same time point. Adverse events (eg, edema and ecchymosis) were mild and transient in both studies.

\section{Conclusion}

Cellulite affects the majority of female patients. Although several purported treatment options exist, many of these either lack standardized supporting evidence or produce ephemeral tissue responses, making their use impractical. Subcision is an established therapy that can lead to significant improvement in the clinical appearance of cellulite with a low adverse event profile. Increasing understanding of the complicated pathophysiology of cellulite will likely enhance current treatment options and lead to the development of more targeted therapies in the near future.

\section{Disclosure}

The authors report no conflicts of interest in this work.

\section{References}

1. Rossi AM, Katz BE. A modern approach to the treatment of cellulite. Dermatol Clin. 2014;32(1):51-59.

2. Rossi AB, Vergnanini AL. Cellulite: a review. J Eur Acad Dermatol Venereol. 2000;14(4):251-262.

3. Avram MM. Cellulite: a review of its physiology and treatment. $J$ Cosmet Laser Ther. 2004;6(4):181-185.

4. Nürnberger F, Müller G. So-called cellulite: an invented disease. J Dermatol Surg Oncol. 1978;4(3):221-229.

5. Emanuele E. Cellulite: advances in treatment: facts and controversies. Clin Dermatol. 2013;31(6):725-730.

6. Piérard GE. Commentary on cellulite: skin mechanobiology and the waist-to-hip ratio. J Cosmet Dermatol. 2005;4(3):151-152.

7. Mirrashed F, Sharp JC, Krause V, Morgan J, Tomanek B. Pilot study of dermal and subcutaneous fat structures by MRI in individuals who differ in gender, BMI, and cellulite grading. Skin Res Technol. 2004;10(3):161-168.

8. Pierard GE, Nizet JL, Piérard-Franchimont C. Cellulite: from standing fat herniation to hypodermal stretch marks. Am J Dermatopathol. 2000;22(1):34-37.
9. Quatresooz P, Xhauflaire-Uhoda E, Piérard-Franchimont C, Pierard GE. Cellulite histopathology and related mechanobiology. Int J Cosmet Sci. 2006;28(3):207-210.

10. Hexsel D, Siega C, Schilling-Souza J, Porto MD, Rodrigues TC. A comparative study of the anatomy of adipose tissue in areas with and without raised lesions of cellulite using magnetic resonance imaging. Dermatol Surg. 2013;39(12):1877-1886.

11. Rosenbaum M, Prieto V, Hellmér J, et al. An exploratory investigation of the morphology and biochemistry of cellulite. Plast Reconstr Surg. 1998;101(7):1934-1939.

12. Hexsel DM, Abreu M, Rodrigues TC, Soirefmann M, Zechmeister Do Prado D, Gamboa MML. Side-by-side comparison of areas with and without cellulite depressions using magnetic resonance imaging. Dermatol Surg. 2009;35(10):1471-1477.

13. Omi T, Sato S, Kawana S. Ultrastructural assessment of cellulite morphology: clues to a therapeutic strategy? Laser Ther. 2013;22(2): 131-136.

14. Querleux B, Cornillon C, Jolivet O, Bittoun J. Anatomy and physiology of subcutaneous adipose tissue by in vivo magnetic resonance imaging and spectroscopy: relationships with sex and presence of cellulite. Skin Res Technol. 2002;8(2):118-124.

15. Curri SB. Cellulite and fatty tissue microcirculation. Cosmet Toilet. 1993;108(4):51-58.

16. Lotti T, Ghersetich I, Grappone C, Dini G. Proteoglycans in so-called cellulite. Int J Dermatol. 1990;29(4):272-274.

17. Emanuele E, Bertona M, Geroldi D. A multilocus candidate approach identifies ACE and HIF1A as susceptibility genes for cellulite. $J$ Eur Acad Dermatol Venereol. 2010;24(8):930-935.

18. Emanuele E, Minoretti P, Altabas K, Gaeta E, Altabas V. Adiponectin expression in subcutaneous adipose tissue is reduced in women with cellulite. Int J Dermatol. 2011;50(4):412-416.

19. Siems W, Grune T, Voss P, Brenke R. Anti-fibrosclerotic effects of shock wave therapy in lipedema and cellulite. Biofactors. 2005;24(1-4): 275-282.

20. Milani GB, Natal Filho A, Amado João SM. Correlation between lumbar lordosis angle and degree of gynoid lipodystrophy (cellulite) in asymptomatic women. Clinics (Sao Paulo). 2008;63(4):503-508.

21. de Godoy JM, de Godoy M de FG. Evaluation of the prevalence of concomitant idiopathic cyclic edema and cellulite. Int J Med Sci. 2011;8(6):453-455.

22. Stavroulaki A, Pramantiotis G. Cellulite, smoking and angiotensinconverting enzyme (ACE) gene insertion/deletion polymorphism. J Eur Acad Dermatol Venereol. 2011;25(9):1116-1117.

23. Hexsel DM, Dal'Forno T, Hexsel CL. A validated photonumeric cellulite severity scale. J Eur Acad Dermatol Venereol. 2009;23(5):523-528.

24. De La Casa Almeida M, Suarez Serrano C, Jiménez Rejano JJ, Chillón Martínez R, Medrano Sánchez EM, Rebollo Roldán J. Intra- and inter-observer reliability of the application of the cellulite severity scale to a Spanish female population. J Eur Acad Dermatol Venereol. 2012;27(6):694-698.

25. Callaghan T, Wilhelm K. An examination of non-invasive imaging techniques in the analysis and review of cellulite. J Cosmet Sci. 2005;56(6):379-393.

26. Bertin C, Zunino H, Pittet JC, et al. A double-blind evaluation of the activity of an anti-cellulite product containing retinol, caffeine, and ruscogenine by a combination of several non-invasive methods. $J$ Cosmet Sci. 2001;52(4):199-210.

27. Bielfeldt S, Buttgereit P, Brandt M, Springmann G, Wilhelm K. Noninvasive evaluation techniques to quantify the efficacy of cosmetic anti-cellulite products. Skin Res Technol. 2008;14(3):336-346.

28. Soares JLM, Miot HA, Sanudo A, Bagatin E. Cellulite: poor correlation between instrumental methods and photograph evaluation for severity classification. Int J Cosmet Sci. 2015;37(1):134-140.

29. Smalls LK, Lee CY, Whitestone J, Kitzmiller WJ, Wickett RR, Visscher MO. Quantitative model of cellulite: three-dimensional skin surface topography, biophysical characterization, and relationship to human perception. J Cosmet Sci. 2005;56(2):105-120. 
30. De La Casa Almeida M, Suarez Serrano C, Jiménez Rejano JJ, Ríos Díaz J, Benitez Lugo ML, Rebollo Roldán JR. Reliability of texture analysis using co-occurrence matrices $(\mathrm{glcm})$ on photographic image in the assessment of cellulite in a Spanish population. J Eur Acad Dermatol Venereol. 2015;29(2):315-324.

31. Khan MH, Victor F, Rao B, Sadick NS. Treatment of cellulite. Part II. Advances and controversies. J Am Acad Dermatol. 2010;62(3): 373-384.

32. Peterson JD, Goldman MP. Laser, light, and energy devices for cellulite and lipodystrophy. Clin Plast Surg. 2011;38(3):463-474.

33. Hexsel D, Dal Forno T, Hexsel C, et al. Magnetic resonance imaging of cellulite depressed lesions successfully treated by subcision. Dermatol Surg. 2016;42(5):693-696.

34. Kaminer MS, Coleman WP, Weiss RA, Robinson DM, Coleman WP, Hornfeldt C. Multicenter pivotal study of vacuum-assisted precise tissue release for the treatment of cellulite. Dermatol Surg. 2015;41(3): 336-347.

35. Turati F, Pelucchi C, Marzatico F, et al. Efficacy of cosmetic products in cellulite reduction: systematic review and meta-analysis. J Eur Acad Dermatol Venereol. 2014;28(1):1-15.

36. Chang P, Wiseman J, Jacoby T, Salisbury AV, Ersek RA. Noninvasive mechanical body contouring: (Endermologie) a one-year clinical outcome study update. Aesthetic Plast Surg. 1998;22(2):145-153.

37. Gold MH. Cellulite - an overview of non-invasive therapy with energybased systems. J Dtsch Dermatol Ges. 2012;10(8):553-558.

38. Latrenta GS, Mick SL. Endermologie after external ultrasoundassisted lipoplasty (EUAL) versus EUAL alone. Aesthet Surg J. 2001;21(2):128-135.

39. Güleç AT. Treatment of cellulite with LPG endermologie. Int J Dermatol. 2009;48(3):265-270.

40. Ortonne JP, Queille-Roussel C, Duteil L, Emiliozzi C, Zartarian M. Treatment of cellulite: effectiveness and sustained effect at 6 months with endermologie demonstrated by several quantitative evaluation methods. Nouv Dermatol. 2004;23:261-269.

41. Adatto M, Adatto-Neilson R, Servant JJ, Vester J, Novak P, Krotz A. Controlled, randomized study evaluating the effects of treating cellulite with AWT®/EPAT®. J Cosmet Laser Ther. 2010;12(4):176-182.
42. Russe E, Juric M, Russe-Wilfingsleder K. Acoustic wave treatment for cellulite - a new approach. Abstracts of the American Society for Laser Medicine and Surgery Twenty-Ninth Annual Meeting. Lasers Surg Med. 2009;41(Suppl 21):81.

43. Schlaudraff K-U, Kiessling MC, Császár NB, Schmitz C. Predictability of the individual clinical outcome of extracorporeal shock wave therapy for cellulite. Clin Cosmet Investig Dermatol. 2014;7:171-183.

44. Knobloch K, Joest B, Krämer R, Vogt PM. Cellulite and focused extracorporeal shockwave therapy for non-invasive body contouring: a randomized trial. Dermatol Ther (Heidelb). 2013;3(2):143-155.

45. Hexsel DM, Mazzuco R. Subcision: a treatment for cellulite. Int $J$ Dermatol. 2000;39(7):539-544.

46. Klein JA. The tumescent technique for liposuction surgery. Am J Cosm Surg. 1987;4:263-267.

47. Klein JA. Tumescent infiltration technique. In: Klein JA, editor. Tumescent Technique: Tumescent Anesthesia and Microcannular Liposuction. Vol St. Louis: Mosby, Inc.; 2000:222-234.

48. Klein JA. Pharmacokinetics of tumescent liposuction. In: Klein JA, editor. Tumescent Technique: Tumescent Anesthesia and Microcannular Liposuction. St. Louis, MO, USA: Mosby, Inc.; 2000:141-161.

49. Green JB, Cohen JL. Cellfina observations: pearls and pitfalls. Semin Cutan Med Surg. 2015;34(3):144-146.

50. Sasaki GH. Single treatment of grades II and III cellulite using a minimally invasive 1,440-nm pulsed Nd:YAG laser and side-firing fiber: an institutional review board-approved study with a 24-month follow-up period. Aesth Plast Surg. 2013;37(6):1073-1089.

51. DiBernardo B, Sasaki G, Katz BE, Hunstad JP, Petti C, Burns AJ. A multicenter study for a single, three-step laser treatment for cellulite using a 1440-nm Nd:YAG laser, a novel side-firing fiber, and a temperature-sensing cannula. Aesthet Surg J. 2013;33(4):576-584.

52. DiBernardo BE, Sasaki GH, Katz BE, Hunstad JP, Petti C, Burns AJ. A multicenter study for cellulite treatment using a 1440-nm Nd:YAG wavelength laser with side-firing fiber. Aesthet Surg J. 2016;36(3):335-343.

53. Katz B. Quantitative \& qualitative evaluation of the efficacy of a 1440 $\mathrm{nm} \mathrm{Nd}$ :YAG laser with novel bi-directional optical fiber in the treatment of cellulite as measured by 3-dimensional surface imaging. J Drugs Dermatol. 2013;12(11):1224-1230.
Clinical, Cosmetic and Investigational Dermatology

\section{Publish your work in this journal}

Clinical, Cosmetic and Investigational Dermatology is an international, peer-reviewed, open access, online journal that focuses on the latest clinical and experimental research in all aspects of skin disease and cosmetic interventions. This journal is included on PubMed. The manuscript management system is completely online
Dovepress

and includes a very quick and fair peer-review system, which is all easy to use. Visit http://www.dovepress.com/testimonials.php to read real quotes from published authors 